\title{
Polymorphisms of DNA damage response genes in radiation-related and sporadic papillary thyroid carcinoma
}

\author{
Natallia M Akulevich ${ }^{1}$, Vladimir A Saenko ${ }^{2}$, Tatiana I Rogounovitch ${ }^{1}$, \\ Valentina M Drozd ${ }^{3}$, Eugeny F Lushnikov', Victor K Ivanov ${ }^{4}$, \\ Norisato Mitsutake ${ }^{1}$, Ryo Kominami ${ }^{5}$ and Shunichi Yamashita ${ }^{1,2}$
}

\author{
Departments of ${ }^{1}$ Molecular Medicine and ${ }^{2}$ International Health and Radiation Research, Nagasaki University Graduate School of \\ Biomedical Sciences, Nagasaki 852-8523, Japan \\ ${ }^{3}$ Department of Thyroid Disease Research, Belarusian Medical Academy for Postgraduate Education, Minsk 220013, Republic of \\ Belarus \\ ${ }^{4}$ Medical Radiological Research Center, Obninsk 249036, Russian Federation \\ ${ }^{5}$ Department of Molecular Genetics, Graduate School of Medical and Dental Sciences, Niigata University, Niigata 951-8122, Japan \\ (Correspondence should be addressed to V A Saenko; Email: saenko@net.nagasaki-u.ac.jp)
}

\begin{abstract}
Papillary thyroid carcinoma (PTC) etiologically occurs as a radiation-induced or sporadic malignancy. Genetic factors contributing to the susceptibility to either form remain unknown. In this retrospective case-control study, we evaluated possible associations between singlenucleotide polymorphisms (SNPs) in the candidate DNA damage response genes (ATM, $X R C C 1, T P 53, X R C C 3, M T F 1)$ and risk of radiation-induced and sporadic PTC. A total of 255 PTC cases (123 Chernobyl radiation-induced and 132 sporadic, all in Caucasians) and 596 healthy controls (198 residents of Chernobyl areas and 398 subjects without history of radiation exposure, all Caucasians) were genotyped. The risk of PTC and SNPs interactions with radiation exposure were assessed by logistic regressions. The ATM G5557A and XRCC1 Arg399GIn polymorphisms, regardless of radiation exposure, associated with a decreased risk of PTC according to the multiplicative and dominant models of inheritance (odds ratio $(O R)=0.69,95 \%$ confidence interval (Cl) $0.45-0.86$ and $\mathrm{OR}=0.70,95 \% \mathrm{Cl} 0.59-0.93$ respectively). The ATMIVS22-77 T $>\mathrm{C}$ and TP53 Arg72Pro SNPs interacted with radiation ( $P=0.04$ and $P=0.01$ respectively). ATM IVS22-77 associated with the increased risk of sporadic PTC $(\mathrm{OR}=1.84,95 \% \mathrm{Cl} 1.10-3.24)$ whereas TP53 Arg72Pro correlated with the higher risk of radiogenic PTC (OR $=1.80,95 \% \mathrm{Cl} 1.06-2.36)$. In the analyses of ATM/TP53 (rs1801516/rs664677/rs609429/rs1042522) combinations, the GG/TC/CG/GC genotype strongly associated with radiation-induced PTC $(\mathrm{OR}=2.10,95 \% \mathrm{Cl}$ 1.17-3.78). The GG/CC/GG/GG genotype displayed a significantly increased risk for sporadic PTC $(\mathrm{OR}=3.32,95 \% \mathrm{Cl} 1.57-6.99)$. The results indicate that polymorphisms of DNA damage response genes may be potential risk modifiers of ionizing radiation-induced or sporadic PTCs.
\end{abstract}

Endocrine-Related Cancer (2009) 16 491-503

\section{Introduction}

Thyroid cancer accounts for more than $90 \%$ of all endocrine malignancies. The incidence of thyroid cancer in the world is increasing during the past three decades, mainly due to the papillary thyroid carcinoma (PTC) which is the predominant type of malignant thyroid tumors (Davies \& Welch 2006).

Most thyroid cancer patients do not have the history of radiation exposure, yet ionizing radiation (IR) is a recognized etiological factor of the disease. An increased risk of thyroid cancer has been documented after external irradiation (Ron et al. 1995) and after environmental exposure to ${ }^{131} \mathrm{I}$, such as after the Chernobyl fallouts in Belarus, Ukraine, and Russia (Bennett et al. 2006).

Although radiation thyroid doses in Chernobyl PTC cases are generally greater than in controls in epidemiological studies (Cardis et al. 2005, Jacob et al. 2006, Likhtarev et al. 2006), thus confirming radiation to be a risk factor for thyroid cancer, those in 
controls are non-zero. Furthermore, there were some 14 million residents in the contaminated territories at the time of exposure (Bennett et al. 2006). Conceivably, at least some of them might have accumulated thyroid doses comparable with doses in diseased individuals. However, thyroid cancer developed only in a small fraction of irradiated population.

Among the variety of DNA damage types induced by radiation, double-strand DNA breaks are considered to be the most significant for chromosomal aberrations, mutagenesis, genetic instability, and carcinogenesis (Khanna \& Jackson 2001). PTC is one of the rare human cancers of epithelial origin in whose oncogenesis gene rearrangements play a noticeable role. Several variants of rearrangements are described in PTC, with RET/PTC occurring most frequently (Nikiforov et al. 1997, Rabes et al. 2000).

While in the exposed individuals DNA damage could be attributed to IR, the origination of genetic alterations in sporadic cancers remains obscure. Nevertheless, the spectrum of oncogenic changes in radiation-related and sporadic PTCs is largely common. Such similarities imply the resemblance of molecular reactions on DNA damage in exposed and non-exposed thyrocytes. These reactions involve first of all DNA damage response factors, including DNA repair and checkpoint complexes.

The vast majority of Chernobyl thyroid malignancies were PTCs which displayed wide variations in clinical course, from highly aggressive tumors developing after the shorter latency to more indolent carcinomas with the longer latent period (Williams 2006). The randomness and multiplicity of forms of genetic alterations caused by IR can only partly explain these differences in the individual reactions on exposure as well as why cancer develops only in some of the exposed individuals.

It is attractive to hypothesize that inherited variability in the genes directly or indirectly involved in the maintenance of genome stability in response to environmental carcinogens such as IR or chemicals that may play a role in susceptibility for radiationrelated or sporadic PTC or may be a marker of it. In this work, we tested the relation of genetic variants of some of such genes, namely ATM, TP53, XRCC1, XRCC3, and MTF 1 to PTC of different etiology.

The ataxia-telangiectasia mutated (ATM) gene plays a key role in the sensing and repair of DNA doublestrand breaks. Activation of the ATM protein kinase by IR results in the subsequent initiation of several molecular pathways of DNA damage repair (Shiloh 2003). One of the ATM targets is the p53 pathway.
Overexpression of TP53 arrests the cell cycle and affects DNA repair and apoptosis.

The ATM and TP53 genes play a significant role especially in the tumors that are induced by IR. A number of single-nucleotide polymorphisms (SNPs) in the ATM and TP53 genes studied in populations of different ethnicities have been reported to associate with the risk of different radiogenic tumors ( $\mathrm{Hu}$ et al. 2002, Angele et al. 2003, Thorstenson et al. 2003, Malmer et al. 2007). By contrast, studies of postChernobyl pediatric thyroid cancers demonstrated a low mutation and polymorphism rate in the TP53 gene (Nikiforov et al. 1996, Hillebrandt et al. 1997). It, however, should be mentioned that after exposure to radiation p53 facilitates DNA repair in normal thyrocytes in vitro (Yang et al. 1997).

The base excision repair (BER) and homologous recombination repair (HRR) pathways are particularly important for genomic integrity restoration (Hoeijmakers 2001). The product of the X-ray repair cross complementing 1 (XRCCl) gene acts as a scaffold and a modulator of different enzymes involved in BER. The XRCCl Arg399Gln and Arg280His variants have been extensively investigated for their function and association with cancer risk; however, the results remain contradictory rather than conclusive (Hu et al. 2005). The XRCC3 gene is a member of the Rad51 DNA-repair gene family. Its product is a factor of the HRR. The XRCC3 Thr241Met polymorphism has been controversially associated with different human malignancies (Han et al. 2006). Sturgis et al. (2005) reported 241Met allele association with the risk of differentiated thyroid cancer.

The metal-responsive transcription factor 1 (MTF1) gene has been implicated in tumor initiation and progression to malignant growth. MTF1 protein interacts with metallothioneins that are able to suppress cellular stresses generated by IR and other agents (Tamura et al. 2005). Polymorphism in murine Mtfl gene has been found to associate with the susceptibility to experimental $\gamma$-ray-induced thymic lymphomas. This observation points at possible involvement of human MTF1 polymorphisms in the modulation of radiation-induced malignancies (Tamura et al. 2005).

To date no polymorphisms of the ATM, XRCC1, and MTF1 genes have been studied neither in human sporadic or radiation-induced PTCs. Data on the TP53 and $X R C C 3$ polymorphisms associations are quite limited (Hillebrandt et al. 1997, Boltze et al. 2002, Granja et al. 2004, Sturgis et al. 2005, Rogounovitch et al. 2006). Therefore, in this study, we addressed the relation of SNPs in aforementioned DNA damage response genes to the risk of PTCs of different etiology. 


\section{Materials and methods}

\section{Study population}

A total of 255 histologically verified PTC cases and 596 healthy controls, all Caucasians, were included in the study. Among the patients, 123 individuals with PTC (24 males and 99 females) lived in the areas of the Russian Federation (38 patients) and Belarus (85 patients) contaminated with radionuclides from Chernobyl fallouts. At the time of the Chernobyl accident, these subjects were younger than 18 years old (mean age at exposure \pm s.D., $9.8 \pm 5.1$ years old; $1-18$ years old, range). The mean age at diagnosis was $24.4 \pm 4.9$ years old, range 19-37 years old (IR-induced PTCs). Information about individual radiation thyroid doses was available for PTC cases from Russia as reconstructed in previous studies (Davis et al. 2004, Stepanenko et al. 2004). The doses varied from 43 to $2640 \mathrm{mGy}$. Radiation thyroid doses for PTC patients and controls from Belarus evaluated in dosimetric investigations at the places of residence ranged 21-1500 mGy (Bouville et al. 2007). Among the controls, 198 individuals (65 males and 133 females, mean age at sampling $22.2 \pm 3.2$ years old; $19-35$ years old, range) were residents of the Chernobyl areas (60 from the Russian Federation and 138 from Belarus). The averaged thyroid radiation dose in the exposed control subjects from Russia is $41 \mathrm{mGy}$ (Bouville et al. 2007). All exposed control individuals were aged $<18$ years at the time of the accident (mean age at exposure $1.8 \pm 3.2$ years old; $1-16$ years old, range) (IR-exposed controls). IR-exposed controls and patients with IR-induced PTCs not were individually matched; however, they were residents of the same settlements. This, given the uncertainty with individual radiation thyroid doses, was supposed to partly reduce exposure bias. Age of IR-exposed control subjects was set to be \pm 3 years of that of IR-induced PTC individuals.

One hundred and thirty-two PTC cases (21 males and 111 females, mean age at diagnosis $47.8 \pm 11.4$ years old; 19-76 years old, range) were adults without history of radiation exposure (sporadic PTCs). The remaining 398 control participants (180 males and 218 females, mean age at sampling $45.0 \pm 10.3$ years old; 16-65 years old, range) had no previous history of radiation exposure (non-exposed controls); their age was also set to be \pm 3 years of that of patients with sporadic PTC. Both sporadic PTCs and non-exposed controls originated from the European part of Russia not contaminated by the Chernobyl fallouts.

Thyroid tissues and/or blood samples were collected from patients during surgery or further follow-up. Blood samples and information from the controls were obtained during a routine health examination or complex screening for thyroid diseases.

Written informed consent was obtained from all participants. Protocols of the present study were approved by the Committee for Ethical Issues of Human Genome Analysis of Nagasaki University.

\section{SNP selection}

The candidate SNPs (Table 1) were selected based on their reported functional role (if available), associations with radiosensitivity or (thyroid) cancer risk. Accordingly, we did not search for tag SNPs or account for the genetic variability in the regions of SNP location. All SNPs are listed in a public database, dbSNP (http://www.ncbi.nlm.nih.gov/SNP/), with validated status in ethnically diverse populations. To ensure sufficient power for calculations, only SNPs with minor allele frequency (MAF) of $>1 \%$ were included.

\section{SNP genotyping}

DNA was extracted from normal thyroid tissues using proteinase $\mathrm{K} /$ phenol-chloroform method or from the whole blood lymphocytes with Puregene DNA Purification Kit (Gentra Systems, Inc., Minneapolis, PA, USA). All specimens were genotyped using various techniques (Table 1). Primers and probes (Table 2) were designed with Primer Express Version 1.0 (Applied Biosystems, Foster City, CA, USA) software.

Briefly, $25 \mu \mathrm{l}$ PCR mixtures generally contained $50 \mathrm{ng}$ DNA, $1.5 \mathrm{mM} \mathrm{MgCl}_{2}, 200 \mu \mathrm{M}$ each dNTP, optimized concentrations of corresponding primers and $0.625 \mathrm{U}$ AmpliTaq Gold (Applied Biosystems). All restriction endonucleases for PCR/RFLP were from New England BioLabs (Ipswich, MA, USA). TaqMan allelic discrimination assay for TP53 variants was done essentially as described previously (Rogounovitch et al. 2006). Melting curve $T_{\mathrm{m}}$-shift assay for MTF1 genotyping was designed according to the described technology (Wang et al. 2005) and done in a Thermal Cycler Dice Real Time System TP800 (TaKaRa, Ohtsu, Japan). Technical details are available from the authors upon request.

For every SNP, some 20-30 randomly chosen DNA samples, unless otherwise specified, were also analyzed by direct sequencing with a Big Dye Terminator sequencing kit v 3.1 (Applied Biosystems) in an ABI Prism 3100 Genetic Analyzer (Applied Biosystems). A complete concordance between different techniques was observed. 


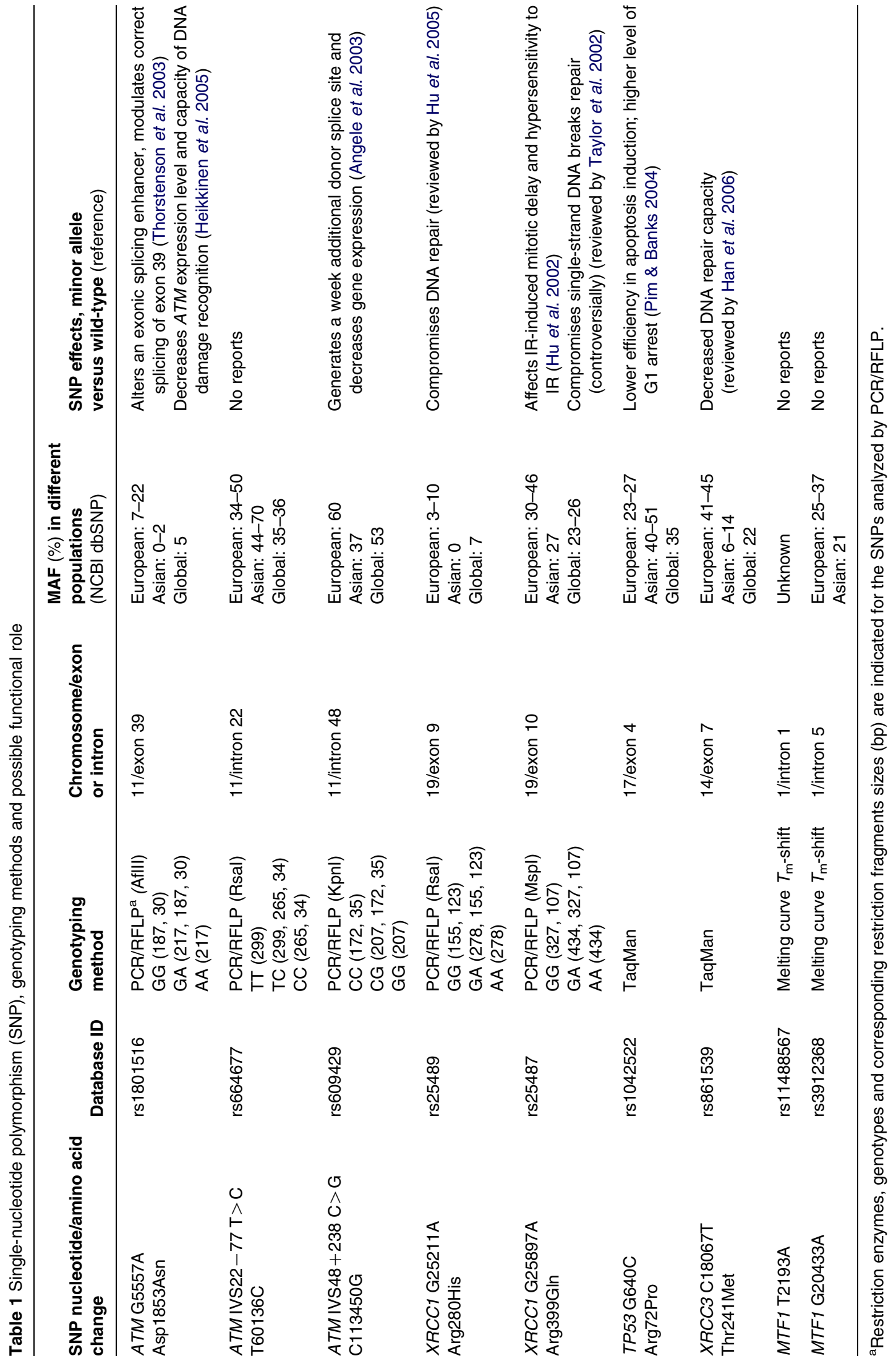


Table 2 Primers and probes for genotyping

\begin{tabular}{|c|c|c|c|}
\hline SNP & Primer/probe sequences $\left(5^{\prime}-3^{\prime}\right)^{\mathrm{a}}$ & $\begin{array}{c}\text { Primer/probe } \\
\text { concentration } \\
(\mu \mathrm{M})\end{array}$ & $\begin{array}{c}\text { Annealing } \\
\text { temperature } \\
\left({ }^{\circ} \mathrm{C}\right)\end{array}$ \\
\hline \multirow[t]{2}{*}{ ATM G5557A } & F: CCATACTTGATTCATGATATTTTACcttAA & 0.2 & 57 \\
\hline & R: TTCCATCTTAAATCСАТСTTTCTC & 0.2 & \\
\hline \multirow[t]{2}{*}{ ATM IVS22-77 T >C } & F: AGTTTAGCACAGAAAGACATATTGGAAGTAACgTA & 0.2 & 57 \\
\hline & R: CGGGAAAAGAACTGTGGTTAAATATGAAA & 0.2 & \\
\hline \multirow[t]{2}{*}{ ATM IVS $48+238 \mathrm{C}>\mathrm{G}$} & F: CTCAATTTCCTGGTTATAAAATGAGAAGgTAC & 0.2 & 57 \\
\hline & R: TTAACTACTTGTCAGGGACTATCTTAAGGAC & 0.2 & \\
\hline \multirow[t]{2}{*}{$X R C C 1 \mathrm{G} 25211 \mathrm{~A}$} & F: GTCTGAGGGAGGAGGGTCTG & 0.2 & 59 \\
\hline & R: TTCTGGAAGCCACTCAGCAC & 0.2 & \\
\hline \multirow[t]{2}{*}{ XRCC1 G25897A } & F: CCACCAGCTGTGCCTTTG & 0.2 & 55 \\
\hline & R: CCGGGACTCACTTTGAATGA & 0.2 & \\
\hline \multirow[t]{4}{*}{ TP53 G640C } & F: CGTCCCAAGCAATGGATGATT & 0.8 & 61 \\
\hline & R: CCGGTGTAGGAGCTGCTGG & 0.8 & \\
\hline & w/t allele probe (FAM): CTCCCCGCGTGGCCCC & 0.4 & \\
\hline & 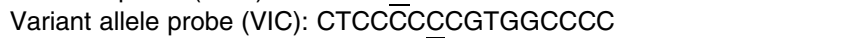 & 0.4 & \\
\hline \multirow[t]{4}{*}{ XRCC3 C18067Т } & F: AGGGCCAGGCATCTGCA $\quad-$ & 0.8 & 61 \\
\hline & R: CTTCCGCATCCTGGCTAA & 0.8 & \\
\hline & w/t allele probe (FAM): TCACGCAGCGTGGCCCCCAG & 0.5 & \\
\hline & Variant allele probe (VIC): TCACGCA $\bar{G} C A T G G C C C C C A G$ & 0.5 & \\
\hline \multirow[t]{3}{*}{ MTF1 T2193A } & 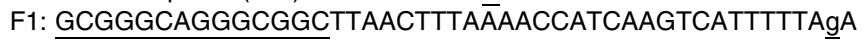 & 0.2 & 58 \\
\hline & 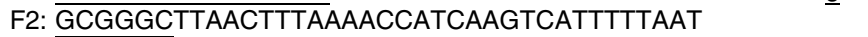 & 0.2 & \\
\hline & R: ACGCCCAGTCGGCATTGCT & 0.2 & \\
\hline \multirow[t]{3}{*}{ MTF1 G20433A } & F1: GCGGGCAGGGCGGCCTAATTATGCTCACCTGAATATATACAGGG & 0.075 & 63 \\
\hline & F2: GCGGGCCTAATTATGCTCACCTGAATATATACAGGA & 0.2 & \\
\hline & R: GAGACCTGTAGAGCTAGGTGGATATACAGAGATAT & 0.2 & \\
\hline
\end{tabular}

${ }^{\mathrm{a}}$ The bases shown in lowercase are mismatches introduced to generate restriction endonuclease sites (PCR/RFLP) or to optimize allelic specificity ( $T_{\mathrm{m}}$-shift). The underlined $5^{\prime}$ portions of primer sequences correspond to GC tails in the $T_{\mathrm{m}}$-shift method.

Raw genotyping outputs were interpreted by at least two independent investigators. Missing results due to genotyping procedure failures accounted for $<1 \%$ for any SNP tested.

\section{Statistical analysis}

Genotype frequencies in each group were determined by univariate analysis and evaluated for departure from Hardy-Weinberg equilibrium by the $\chi^{2}$ test. SNP associations with PTC were assessed by multivariate logistic regression analysis for codominant, multiplicative, dominant, and recessive models to avoid assumptions regarding the mode of inheritance (see notes below Table 4). All analyses were adjusted for gender (male or female, nominal), age (years, continuous), and IR-exposure (yes or no, nominal). Besides all the parameters above, the full model included disease status (yes or no, nominal) and, depending on the mode of inheritance, genotype for each SNP (nominal variable in the codominant, dominant, and recessive models and ordinal in the multiplicative model).

Power calculations were done with the PS software (http://biostat.mc.vanderbilt.edu/twiki/bin/view/Main/ PowerSampleSize). With given sample size, the study had a power of 54-99\% to detect an OR of 2.0 at the significance level of 5\% with MAF ranging 4-45\%.

Interaction between SNPs, cancer and radiation exposure were hypothesized a priori and evaluated by multivariate analysis with corresponding adjustments. Separate calculations of OR were done in irradiated and non-exposed case-control groups when $P$ value for an interaction term did not exceed 0.05.

Statistical analysis was done using SPSS for Windows version 17.0 (SPSS, Inc., Chicago, IL, USA).

\section{Results}

The distribution of genotypes and MAF for each SNP in the four study groups is shown in Table 3. The observed distributions in the control groups were not statistically different from those expected from HardyWeinberg equilibrium for all SNP except for ATM G5557A and ATM IVS22-77 T $>C$ in the non-exposed controls. Since such deviation might point at possible genotyping error (Hosking et al. 2004), we reanalyzed 96 non-exposed controls for these SNPs by direct sequencing. There were no inconsistencies between PCR/RFLP and sequencing results (data not shown) ruling out technical flaw. Furthermore, allelic frequencies determined in our study are in a good agreement 
N M Akulevich et al.: Genotypes of PTC of different etiology

Table 3 Distribution of genotypes and minor allele frequencies by study groups

\begin{tabular}{|c|c|c|c|c|}
\hline SNP, genotype & $\begin{array}{l}\text { IR-induced PTC } \\
n(\%)\end{array}$ & $\begin{array}{l}\text { IR-exposed controls } \\
n(\%)\end{array}$ & $\begin{array}{l}\text { Sporadic PTC } \\
n(\%)\end{array}$ & $\begin{array}{l}\text { Non-exposed controls } \\
n(\%)\end{array}$ \\
\hline ATM G5557A & $n=122$ & $n=198$ & $n=132$ & $n=398$ \\
\hline$G G$ & $95(77.9)$ & $138(69.7)$ & $105(79.5)$ & $293(73.6)$ \\
\hline$G A$ & $25(20.5)$ & $53(26.8)$ & $24(18.2)$ & $90(22.6)$ \\
\hline$A A$ & $2(1.6)$ & $7(3.5)$ & $3(2.3)$ & $15(3.8)$ \\
\hline$P$ & 0.24 & & 0.36 & \\
\hline$A, \%$ & 11.9 & 16.9 & 11.4 & 15.1 \\
\hline ATM IVS22-77 T $>C$ & $n=123$ & $n=195$ & $n=132$ & $n=398$ \\
\hline$T T$ & $35(28.4)$ & $62(31.8)$ & $45(34.1)$ & $135(33.9)$ \\
\hline$T C$ & $76(61.8)$ & $102(52.3)$ & $61(46.2)$ & 216 (54.3) \\
\hline$C C$ & $12(9.8)$ & $31(15.9)$ & $26(19.7)$ & $47(11.8)$ \\
\hline$P$ & 0.17 & & 0.06 & \\
\hline$C, \%$ & 40.6 & 42.0 & 42.8 & 38.9 \\
\hline ATM IVS48+238 C > G & $n=122$ & $n=196$ & $n=132$ & $n=398$ \\
\hline$C C$ & $37(30.3)$ & $68(34.7)$ & $41(31.1)$ & $131(32.9)$ \\
\hline$C G$ & $69(56.6)$ & $97(49.5)$ & $61(46.2)$ & $201(50.5)$ \\
\hline$G G$ & $16(13.1)$ & $31(15.8)$ & $30(22.7)$ & $66(16.6)$ \\
\hline$P$ & 0.47 & & 0.28 & \\
\hline$G, \%$ & 41.4 & 40.3 & 45.8 & 41.8 \\
\hline$X R C C 1 \mathrm{Arg}^{280 \mathrm{His}^{\mathrm{a}}}$ & $n=123$ & $n=195$ & $n=132$ & $n=398$ \\
\hline$G G$ & $113(91.9)$ & $176(90.3)$ & $117(88.6)$ & 366 (92.0) \\
\hline$G A$ & $10(8.1)$ & $19(9.7)$ & $15(11.4)$ & $32(8.0)$ \\
\hline$P$ & 0.63 & & 0.24 & \\
\hline$A, \%$ & 4.1 & 4.9 & 5.7 & 4.0 \\
\hline XRCC1 Arg399GIn & $n=123$ & $n=197$ & $n=132$ & $n=398$ \\
\hline$G G$ & $55(44.7)$ & $75(38.1)$ & $65(49.2)$ & $158(39.7)$ \\
\hline$G A$ & $50(40.7)$ & $100(50.7)$ & $53(40.2)$ & $193(48.5)$ \\
\hline$A A$ & $18(14.6)$ & $22(11.2)$ & $14(10.6)$ & $47(11.8)$ \\
\hline$P$ & 0.20 & & 0.15 & \\
\hline$A, \%$ & 35.1 & 36.5 & 30.7 & 36.1 \\
\hline TP53 Arg72Pro & $n=122$ & $n=197$ & $n=129$ & $n=395$ \\
\hline$G G$ & $53(43.4)$ & $115(58.4)$ & $69(53.5)$ & $196(49.6)$ \\
\hline$G C$ & $57(46.7)$ & $73(37.0)$ & $49(38.0)$ & $161(40.8)$ \\
\hline$C C$ & $12(9.9)$ & $9(4.6)$ & $11(8.5)$ & $38(9.6)$ \\
\hline$P$ & 0.02 & & 0.74 & \\
\hline$C, \%$ & 33.2 & 23.1 & 27.5 & 30.0 \\
\hline XRCC3 Thr241Met & $n=120$ & $n=198$ & $n=132$ & $n=398$ \\
\hline$C C$ & $53(44.2)$ & $82(41.4)$ & $55(41.7)$ & $161(40.5)$ \\
\hline$C T$ & $51(42.5)$ & $89(45.0)$ & 65 (49.2) & 192 (48.2) \\
\hline$T T$ & 16 (13.3) & 27 (13.6) & $12(9.1)$ & 45 (11.3) \\
\hline$P$ & 0.89 & & 0.78 & \\
\hline$T, \%$ & 34.6 & 36.1 & 33.7 & 35.4 \\
\hline MTF1 T2193A & $n=122$ & $n=198$ & $n=131$ & $n=397$ \\
\hline$T T$ & 45 (36.9) & $82(41.4)$ & 44 (33.6) & $133(33.5)$ \\
\hline$T A$ & $64(52.5)$ & $91(46.0)$ & $67(51.1)$ & $188(47.4)$ \\
\hline$A A$ & 13 (10.6) & $25(12.1)$ & 20 (15.3) & $76(19.1)$ \\
\hline$P$ & 0.52 & & 0.57 & \\
\hline$A, \%$ & 36.8 & 35.6 & 40.8 & 42.8 \\
\hline MTF1 G20433A & $n=123$ & $n=198$ & $n=132$ & $n=398$ \\
\hline$G G$ & $62(50.4)$ & $100(50.5)$ & $66(50.0)$ & $192(48.2)$ \\
\hline$G A$ & $53(43.1)$ & $88(44.4)$ & $56(42.4)$ & $151(38.0)$ \\
\hline$A A$ & $8(6.5)$ & $10(5.1)$ & $10(7.6)$ & $55(13.8)$ \\
\hline$P$ & 0.85 & & 0.16 & \\
\hline$A, \%$ & 28.0 & 27.3 & 28.8 & 32.8 \\
\hline
\end{tabular}

NOTE. Total numbers of samples in each group vary slightly due to genotyping procedures failures.

${ }^{a}$ There was no homozygous (A/A) variant of XRCC1 Arg280His among all samples tested. 
with those specified for Caucasians in the dbSNP (build 129, April 2008, Table 1) thus attesting to the appropriate data quality.

As seen from Table 4, an association between ATM G5557A and PTC, regardless of radiation exposure, was found. The presence of the A allele significantly decreased PTC risk compared with wild-type G allele in the multiplicative model of inheritance $(\mathrm{OR}=0.69$, $95 \%$ CI $0.45-0.86, P=0.03$ ), which is useful for risk comparison between the groups based on the analysis of allelic frequencies in them.

Main effect on PTC risk appeared also significant for the XRCCl gene Arg399Gln polymorphism. The presence of the minor 399Gln allele decreased PTC risk compared with the $\mathrm{Arg} / \mathrm{Arg}$ genotype $(\mathrm{OR}=0.66$, 95\% CI $0.57-0.88, P=0.02$ and $\mathrm{OR}=0.70,95 \% \mathrm{CI}$ $0.59-0.93, P=0.03$, in the co-dominant and dominant models respectively).

Analysis of combined ATM G5557A and XRCC1 Arg399Gln genotypes demonstrated that increasing number of minor alleles (i.e. ATM 5557A and XRCCI 399GIn) significantly decreased PTC risk in corresponding individuals in comparison with those who do not carry minor alleles (Fig. 1).

No other SNP in any gene showed a significant main effect on PTC.

For ATM IVS22-77 $\mathrm{T}>\mathrm{C}$ and TP53 Arg72Pro, evidence for interaction between radiation exposure and PTC was found ( $P$ for interaction 0.04 and 0.01 respectively). As shown in Table 5, the analyses performed in IR-exposed and non-irradiated patients compared respectively, with irradiated and nonexposed controls revealed a significantly increased risk of sporadic PTC for the ATM IVS22-77 homozygous $\mathrm{CC}$ genotype carriers compared with the $\mathrm{TC}+\mathrm{TT}$ genotypes (the recessive model of inheritance, $\mathrm{OR}=1.84,95 \%$ CI $1.10-3.24, P=0.03$ ), whereas in the irradiated group an insignificant inverse effect of these genotypes was observed $(\mathrm{OR}=0.59$, 95\% CI $0.28-1.27, P=0.17$ ). For TP53 codon 72 polymorphism, in all but the recessive models the increased risk of IR-induced PTC as compared with IR-exposed controls was observed. The highest risk of radiogenic PTC was in the co-dominant model $(\mathrm{OR}=2.33,95 \%$ CI $1.15-7.21, P=0.03)$. A significant risk was also found in the multiplicative model of inheritance (OR $=1.70,95 \%$ CI 1.17-2.46, $P=0.006)$. In addition, comparison between IR-exposed and nonexposed controls did not reveal statistically significant difference in adjusted distributions of these polymorphisms. In healthy subjects, the strongest association for the ATM IVS22-77 $\mathrm{T}>\mathrm{C}$ was in the recessive model $(\mathrm{OR}=1.38,95 \%$ CI $0.84-2.26$,
$P=0.21)$ and in the multiplicative model for $T P 53$ Arg72Pro $(\mathrm{OR}=0.70,95 \%$ CI $0.52-1.19, P=0.11)$ further emphasizing possible role of these SNPs in PTC of different etiology.

Considering multiple pathways for repairing diverse DNA damages induced by endogenous and exogenous carcinogens, genetic variants in different repair pathways may probably have a joint effect on cancer risk. In attempt to search for the stronger associations between PTC and studied SNPs, we performed the analyses of genotype combinations for the ATM and TP53 polymorphisms as these genes are functionally related and three out of four SNPs included in our study showed effects on PTC. Among the possible ATM/TP53 combinations (rs1801516/rs664677/rs609429/rs1042522) tested, two demonstrated significant differences in the subsets of both groups of PTCs (Fig. 2). Particularly, the combined ATM/TP53 GG/TC/CG/GC genotype was strongly associated with the IR-induced PTC $(\mathrm{OR}=2.10,95 \%$ CI $1.17-3.78, P=0.015)$. Another ATM/TP53 combination, GG/CC/GG/GG, demonstrated a significantly increased risk for sporadic PTC $(\mathrm{OR}=3.32,95 \%$ CI $1.57-6.99, P=0.002)$.

\section{Discussion}

Our study addressed possible associations between SNPs in the genes involved in DNA damage response and the risk of PTC of different etiology. The results demonstrated that the presence of the variant 5557A allele in exon 39 of ATM and XRCC1 399Gln allele, particularly in the heterozygous state, significantly associated with the decreased risk of PTC. The ATM IVS22-77 CC genotype in the non-exposed group and the TP53 72Pro allele in the radiation-related one associated with the increased risk of PTC. Moreover, two particular ATM/TP53 combined genotypes were found with higher frequencies in the IR-induced or sporadic PTC when compared with the controls. Altogether, these data indicate that SNPs in the studied genes may likely modify PTC risk.

A significant association between the ATM G5557A and bilateral breast cancer in Caucasian patients has been shown before (Heikkinen et al. 2005). Also, this SNP has been reported as a possible modulator of clinical radiosensitivity in cancer. The ATM 5557A allele was associated with severe adverse effects of radiation therapy in prostate (Hall et al. 1998) and breast cancer patients (Angele et al. 2003). Later, an enhanced radiosensitivity of human fibroblasts in the presence of the ATM 5557A allele was demonstrated in an experimental work (Alsbeih et al. 2007). In contrast 
N M Akulevich et al.: Genotypes of PTC of different etiology

Table 4 OR $(95 \% \mathrm{Cl})$ for papillary thyroid carcinoma (PTC) by gene polymorphism according to different models of inheritance (adjusted for age, gender and radiation exposure). $P<0.05$ in bold

\begin{tabular}{|c|c|c|c|}
\hline SNP & Genotype & OR $(95 \% \mathrm{Cl})$ & $\boldsymbol{P}$ \\
\hline \multirow[t]{6}{*}{ ATM G5557A } & $G G$ & $1.00^{\mathrm{a}}$ & \\
\hline & $G A$ & $0.75(0.49-1.15)$ & 0.31 \\
\hline & AA & $0.61(0.21-1.77)$ & 0.45 \\
\hline & Risk per $A$ allele ${ }^{b}$ & $0.69(0.45-0.86)$ & 0.03 \\
\hline & $G A+A A$ versus $G G^{c}$ & $0.73(0.48-1.10)$ & 0.13 \\
\hline & $A A$ versus $G A+G G^{\mathrm{d}}$ & $0.65(0.23-1.87)$ & 0.41 \\
\hline \multirow[t]{6}{*}{ ATM IVS22-77 T>C } & $T T$ & 1.00 & \\
\hline & $T C$ & $1.03(0.70-1.50)$ & 0.74 \\
\hline & $C C$ & $1.19(0.70-2.04)$ & 0.47 \\
\hline & Risk per $C$ allele & $1.08(0.83-1.40)$ & 0.57 \\
\hline & $T C+C C$ versus $T T$ & $1.06(0.74-1.53)$ & 0.75 \\
\hline & $C C$ versus $T C+T T$ & $1.17(0.72-1.90)$ & 0.52 \\
\hline \multirow[t]{6}{*}{ ATM IVS $48+238 \mathrm{C}>\mathrm{G}$} & $C C$ & 1.00 & \\
\hline & $C G$ & $1.10(0.75-1.62)$ & 0.55 \\
\hline & $G G$ & $1.14(0.69-1.89)$ & 0.84 \\
\hline & Risk per $G$ allele & $1.07(0.84-1.37)$ & 0.57 \\
\hline & $C G+G G$ versus $C C$ & $1.11(0.77-1.60)$ & 0.57 \\
\hline & $G G$ versus $C G+C C$ & $1.08(0.69-1.69)$ & 0.74 \\
\hline \multirow[t]{3}{*}{$X R C C 1 \mathrm{Arg}^{2} 80 \mathrm{His}^{\mathrm{e}}$} & $G G$ & 1.00 & \\
\hline & $G A$ & $1.12(0.62-2.01)$ & 0.71 \\
\hline & Risk per $A$ allele & $1.15(0.70-1.87)$ & 0.61 \\
\hline \multirow[t]{6}{*}{ XRCC1 Arg399GIn } & $G G$ & 1.00 & \\
\hline & $G A$ & $0.66(0.57-0.88)$ & 0.02 \\
\hline & AA & $0.88(0.50-1.57)$ & 0.56 \\
\hline & Risk per $A$ allele & $0.90(0.69-1.17)$ & 0.41 \\
\hline & $G A+A A$ versus $G G$ & $0.70(0.59-0.93)$ & 0.03 \\
\hline & $A A$ versus $G A+G G$ & $0.98(0.57-1.69)$ & 0.94 \\
\hline \multirow[t]{6}{*}{ TP53 Arg72Pro } & $G G$ & 1.00 & \\
\hline & $G C$ & $1.02(0.70-1.47)$ & 0.89 \\
\hline & $\mathrm{CC}$ & $1.16(0.63-2.14)$ & 0.38 \\
\hline & Risk per $C$ allele & $1.05(0.81-1.38)$ & 0.70 \\
\hline & $G C+C C$ versus $G G$ & $1.04(0.74-1.48)$ & 0.82 \\
\hline & $C C$ versus $G C+G G$ & $1.15(0.64-2.08)$ & 0.64 \\
\hline \multirow[t]{6}{*}{ XRCC3 Thr241Met } & $C C$ & 1.00 & \\
\hline & $C T$ & $0.99(0.69-1.44)$ & 0.99 \\
\hline & $T T$ & $0.96(0.54-1.70)$ & 0.92 \\
\hline & Risk per $T$ allele & $0.99(0.76-1.28)$ & 0.92 \\
\hline & $C T+T T$ versus $C C$ & $0.99(0.70-1.41)$ & 0.97 \\
\hline & $T T$ versus $C T+C C$ & $0.96(0.56-1.64)$ & 0.88 \\
\hline \multirow[t]{6}{*}{ MTF1 T2193A } & $T T$ & 1.00 & \\
\hline & $T A$ & $1.07(0.73-1.56)$ & 0.61 \\
\hline & $A A$ & $0.83(0.49-1.41)$ & 0.46 \\
\hline & Risk per $A$ allele & $0.94(0.73-1.21)$ & 0.63 \\
\hline & $T A+A A$ versus $T T$ & $1.00(0.70-1.44)$ & 0.99 \\
\hline & $A A$ versus $T A+T T$ & $0.80(0.49-1.29)$ & 0.35 \\
\hline \multirow[t]{6}{*}{ MTF1 G20433A } & $G G$ & 1.00 & \\
\hline & $G A$ & $1.14(0.79-1.63)$ & 0.43 \\
\hline & AA & $0.76(0.40-1.43)$ & 0.21 \\
\hline & Risk per $A$ allele & $0.97(0.74-1.25)$ & 0.80 \\
\hline & $G A+A A$ versus $G G$ & $1.05(0.76-1.49)$ & 0.76 \\
\hline & $A A$ versus $G A+G G$ & $0.71(0.39-1.32)$ & 0.27 \\
\hline
\end{tabular}

${ }^{a}$ Codominant model of inheritance (wild-type homozygous genotype serves as the reference).

${ }^{\mathrm{b}}$ Multiplicative model of inheritance (uses allele frequencies).

'Dominant inheritance model (combined heterozygous and homozygous for the minor allele versus wild-type homozygous).

${ }^{\mathrm{d}}$ Recessive inheritance model (minor allele homozygous versus combined heterozygous and homozygous for the wild-type allele).

${ }^{\mathrm{e}}$ The dominant and recessive models are not shown for XRCC1 Arg280His because of the absence of homozygous (A/A) genotype among 848 samples tested. 


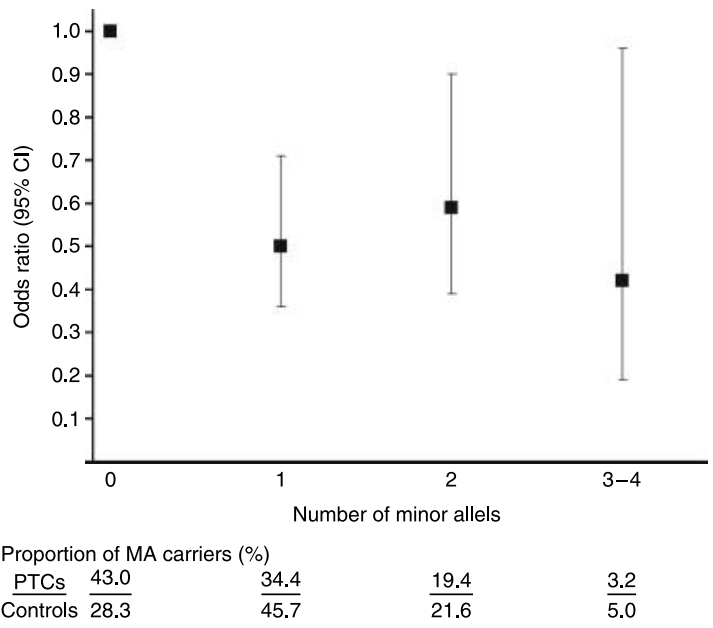

Figure 1 Effect of increasing number of minor alleles (MA) for ATM G5557A and XRCC1 Arg399GIn (minor alleles, ATM 5557A, and XRCC1 399GIn) on PTC risk. The combined genotype with 0 MA was used as a reference. $P$ values for genotypes with different MA number: $P_{1 \mathrm{MA}}<0.0001$; $P_{2 \mathrm{MA}}<0.01 ; P_{3-4 \mathrm{MA}}<0.05$. Carriers of three and four minor alleles were combined because of the exceedingly low number of 4 MA carriers in both PTC and control groups.

to these reports, Edvardsen et al. (2007) revealed an increasing rate of side effects of radiotherapy with decreasing frequency of this variant allele. Our data are rather in agreement with the latter report and favor the protective role of the ATM 5557A allele in PTC development.

The intronic ATM polymorphisms IVS22-77 T $>C$ and IVS48 $+238 \mathrm{C}>\mathrm{G}$ in the homozygous state have been associated with increased breast cancer risk and in the heterozygous state with clinical radioprotection (Angele et al. 2003). These findings were confirmed in the in vitro experiments using lymphoblastoid cell lines established from corresponding patients. Our investigation demonstrated the association between the IVS22-77 CC genotype and increased risk of sporadic PTC in adult patients. By contrast, in the IR-induced PTC group, there was an inverse non-insignificant correlation for this genotype. At the same time, in the IR-induced PTCs, the number of patients heterozygous for IVS22-77 was somewhat, but insignificantly, higher as compared with sporadic PTCs (Table 3). The results for the IVS48+238 $\mathrm{C}>\mathrm{G}$ tended to parallel those for the IVS22-77 $\mathrm{T}>\mathrm{C}$ remaining below the threshold of significance. At present, the mechanistic and functional basis for the intronic ATM SNPs implications in cancer revealed in the previous studies and in ours as well is not fully understood. In a broader sense, however, they may be indicative of a role for the ATM gene (or its product) in the development of PTC.

As reviewed by $\mathrm{Hu}$ et al. (2005), the results of the XRCC1 gene Arg399Glu investigations vary in different cancers for populations with different ethnicities. In relation to cancer and radiation, the 399Gln allele in combination with $280 \mathrm{His}$ was associated with breast cancer risk, and in pair with 194Trp with clinical radiosensitivity in Caucasian women with breast cancer. Also, the 399Gln allele was found to decrease

Table 5 OR $(95 \% \mathrm{Cl})$ for papillary thyroid carcinoma (PTC) of different etiology by ATM and TP53 polymorphisms (adjusted for gender and age). $P<0.05$ in bold

\begin{tabular}{|c|c|c|c|c|c|}
\hline \multirow[b]{2}{*}{ SNP } & \multirow[b]{2}{*}{ Genotype } & \multicolumn{2}{|c|}{$\begin{array}{l}\text { IR-induced PTC versus } \\
\text { IR-exposed controls }\end{array}$} & \multicolumn{2}{|c|}{$\begin{array}{l}\text { Sporadic PTC versus } \\
\text { non-exposed controls }\end{array}$} \\
\hline & & OR (95\% Cl) & $P$ & OR (95\% Cl) & $P$ \\
\hline \multirow[t]{6}{*}{ ATM IVS22-77 T >C } & $T T$ & $1.00^{\mathrm{a}}$ & & 1.00 & \\
\hline & $T C$ & $1.38(0.80-2.39)$ & 0.19 & $0.82(0.51-1.32)$ & 0.50 \\
\hline & $C C$ & $0.73(0.31-1.70)$ & 0.44 & $1.63(0.87-3.08)$ & 0.09 \\
\hline & Risk per $C$ allele ${ }^{b}$ & $0.97(0.66-1.41)$ & 0.86 & $1.18(0.86-1.62)$ & 0.32 \\
\hline & $T C+C C$ versus $T T^{\mathrm{C}}$ & $1.23(0.72-2.10)$ & 0.44 & $0.97(0.62-1.52)$ & 0.88 \\
\hline & $C C$ versus $T C+T T^{\mathrm{d}}$ & $0.59(0.28-1.27)$ & 0.17 & $1.84(1.10-3.24)$ & 0.03 \\
\hline \multirow[t]{6}{*}{ TP53 Arg72Pro } & $G G$ & 1.00 & & 1.00 & \\
\hline & $G C$ & $1.68(1.11-2.75)$ & 0.03 & $0.84(0.53-1.33)$ & 0.52 \\
\hline & $C C$ & $2.33(1.15-7.21)$ & 0.03 & $0.84(0.39-1.79)$ & 0.73 \\
\hline & Risk per $C$ allele & $1.70(1.17-2.46)$ & 0.006 & $0.89(0.64-1.23)$ & 0.47 \\
\hline & $G C+C C$ versus $G G$ & $1.80(1.06-2.36)$ & 0.01 & $0.84(0.54-1.29)$ & 0.43 \\
\hline & $C C$ versus $G C+G G$ & $2.06(0.79-5.41)$ & 0.14 & $0.90(0.44-1.88)$ & 0.79 \\
\hline
\end{tabular}

${ }^{a}$ Codominant model of inheritance (wild-type homozygous genotype serves as the reference).

${ }^{b}$ Multiplicative model of inheritance (uses allele frequencies).

'Dominant inheritance model (combined heterozygous and homozygous for the minor allele versus wild-type homozygous).

${ }^{\mathrm{d}}$ Recessive inheritance model (minor allele homozygous versus combined heterozygous and homozygous for the wild-type allele). 


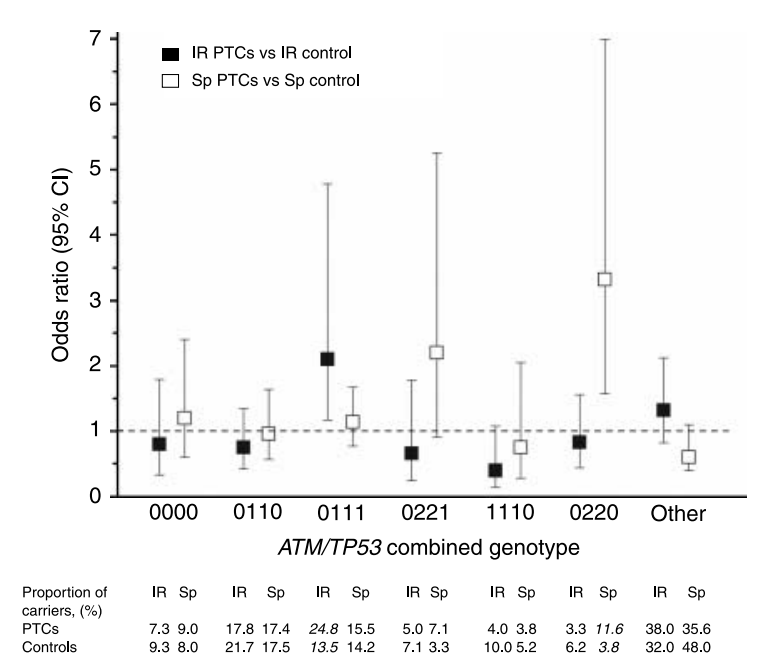

Figure 2 The combined ATM/TP53 genotypes and risk of PTC of different etiology. The combined genotypes were analyzed separately in the IR-exposed and sporadic PTCs versus corresponding control. Six combinations of 3 ATM and 1 TP53 SNPs (rs1801516/rs664677/rs609429/rs1042522) whose frequencies were higher than $5 \%$ at least in two of four subgroups are shown. In the numerical codes for any SNP, 0 - the genotype with no MA (i.e. homozygous wild-type); 1 - 1 MA presents (heterozygous genotype); $2-2$ MA present (homozygous variant genotype); first three numbers correspond to 3 ATM SNPs and the last one to TP53 polymorphism. In the figure, the GG/TT/CC/GG genotype is represented by the '0000' numerical code as it does not contain minor alleles; the $G G / T C / C G / G G$ corresponds to 0110 , GG/TC/CG/GC to 0111; GG/CC/GG/GC to 0221;

$G A / T C / C G / G G$ to 1110 , and $G G / C C / G G / G G$ to 0220 . All combinations with frequencies $<5 \%$ in three or more subgroups are pooled and indicated as 'other'.

the risk of bladder cancer and squamous cell carcinoma of the head and neck.

Interestingly, not only variant but also wild-type allele (i.e. XRCC1 399Arg) demonstrated possible role in cancer. High-dose radiation to the chest was more strongly associated with breast cancer among white American women with XRCC1 Arg399Arg genotype (Duell et al. 2001). Looking for potential biological explanations for these findings, the authors found a higher prevalence of TP53 deletions in the Arg399Arg cases exposed to occupational radiation compared with exposed patients with the Gln399Gln genotypes or unexposed cases of either genotype. Figueiredo et al. (2004) observed an increased risk of disease among wild-type homozygous (Arg/Arg) and heterozygous Canadian Caucasian women with a family history of breast cancer compared with the individuals without such.

The described above data may be explained, at least in part, by the results of functional study of this polymorphism in which an equal ability for both alleles to suffice single strand break repair by XRCCI has been found (Taylor et al. 2002). The results of our study, taken together with those reported previously, suggest that XRCC1 polymorphism in particular the Arg399Gln genotype may influence PTC risk, perhaps by modifying the effects of environmental exposure and/or through interaction with other genetic factors.

The TP53 Arg72Pro polymorphism affects the biological activity of p53. The Arg72 form is more efficient at inducing apoptosis while the Pro72 appears to induce a higher level of G1 arrest (Pim \& Banks 2004). Based on these findings, a number of studies have attempted to assess a correlation between TP53 codon 72 polymorphism and risk of certain types of cancer, however, with inconsistent results, as reviewed by Pietsch et al. (2006). This inconsistency may possibly be explained in part by the coexistence of the codon 72 polymorphism and gain of function mutations in TP53 in some tumors (Pietsch et al. 2006, Soussi \& Wiman 2007).

Several groups have investigated the TP53 Arg72Pro polymorphism in PTC. Boltze et al. (2002) found a small number of heterozygotes and no Pro/Pro genotype in differentiated thyroid carcinomas from Germany. By contrast, in ethnically heterogeneous Brazilian population, the Pro/Pro genotype was associated with the higher risk of differentiated thyroid cancer (Granja et al. 2004). The study of codon 72 polymorphism in thyroid tumors from Russian and Ukrainian patients demonstrated a significantly lower frequency of wild-type homozygotes (i.e. Arg/Arg) among adults with IR-induced PTC when compared with sporadic PTC cases and general population (Rogounovitch et al. 2006). Data obtained in the present work, using an independent set of samples, confirm these findings suggesting the modifying role (or as of a marker) of the TP53 Arg72Pro polymorphism in PTC developed after exposure to IR which is further supported by the absence of significant difference in genotype distributions among our two control groups.

As shown in a genetic study, frequencies of the $C$ allele (encoding 72Pro) do not generally differ in populations of Belarus and Russia (Khrunin et al. 2005). However, East Slavs do not form a single genetic cluster on multidimensional analysis. The 72Pro allele frequency in Belarus is about 0.3; in the two different subpopulations from the Central and Northern regions of the European part of Russia it is 0.24 and 0.32 respectively. The study of healthy population from Poland (bordering with Belarus, linguistically and culturally similar), reported the frequency of 0.28 for the 72Pro allele (Siddique et al. 2005). The 72Pro frequency reported by 
Rogounovitch et al. (2006) in Russian healthy controls is also 0.28 . Thus, the effect of population admixtures in the controls in our investigation could not be completely ruled out. Yet on the other hand, the ratio of Belarusian and Russian subjects in the IR-exposed PTCs and controls was similar (2.24 and 2.30 respectively) suggestive of an unbiased estimate and being an argument in support of TP53 Arg72Pro polymorphism association with radiation-related PTC.

While many studies established the effect of individual SNPs on cancer, the role of SNP combinations has been less addressed. Several ATM and TP53 haplotypes were associated with clinical radiosensitivity in breast cancer (Angele et al. 2003) and brain tumor risk (Malmer et al. 2007). Recently, the interactions of SNPs located on different chromosomes were investigated in various malignancies (Yen et al. 2008, Yoon et al. 2008). One experimental study, in which ATM Asp1853Asn, TP53 Arg72Pro, XRCC1 Arg399Gln, and XRCC3 Thr241Met were genotyped, demonstrated that the increasing number of risk alleles enhanced radiosensitivity of human fibroblast cell lines and, potentially, susceptibility to radiation-induced cancers (Alsbeih et al. 2007). So far no studies have investigated the joint effect of gene polymorphisms on thyroid cancer. Our observations demonstrated that frequencies of particular combined ATM/TP53 genotypes were higher in patients with radiogenic or sporadic PTC compared with corresponding control populations.

To some extent these results support the idea that genetic factors may possibly modify predisposition to thyroid cancer. A recent study by Detours et al. (2007) reported difference in the expression levels of some genes between Chernobyl PTCs from Ukraine and French sporadic PTCs. Although the mentioned work and the present one are different in molecular approaches, the results of both are suggestive of a possible genetic 'susceptibility signature' that may contribute to the individual predisposition to IR and other carcinogens' effects. These findings are in favor of a 'susceptibility model' that may partly explain why only a minority of the large population exposed to the IR after the Chernobyl disaster developed thyroid cancer (Yamashita \& Saenko 2006, Detours et al. 2007, 2008).

It is necessary to note that even though nine SNPs were analyzed in our study, no correction for multiple comparisons was applied because of study design and techniques employed. The associations were tested in a one-at-a-time fashion in a limited sample size in the difficult to access groups. The need for correction in such circumstances is still debated (Rothman \&
Greenland 1998). Furthermore, since data obtained in this work may be referred to as an initial screening result, non-adjusted presentation enables their inclusion in future meta-analysis. Effects of candidate SNPs that we report need validation in other studies.

In conclusion, the results presented here show that SNPs in ATM exon 39 and XRCC1 exon 10 may be the markers of a decreased PTC risk in adults, whereas the ATM IVS22-77 and TP53 codon 72 SNPs genes may associate with the risk of PTC development in nonirradiated and irradiated individuals. To the best of our knowledge, presented here is the first study of this kind reporting the results of genotyping of candidate DNA damage response genes in irradiated and non-irradiated PTC patients and in corresponding healthy populations. Our data support the paradigm of genetic modifiers of radiation-associated carcinogenesis and perhaps may contribute to genetic determination of PTC-prone subjects. We believe such identification will allow future personalized cancer risk prediction which is of a significant importance in view of the growing thyroid cancer incidence and also because of the relevance to occupational and radiation emergency medicine issues.

\section{Declaration of interest}

The authors declare no potential conflict of interest.

\section{Funding}

This work was supported in part by Grant-in-Aid for Scientific Research 19256003, 19510058, and 19790651 from Japan Society for the Promotion of Science.

\section{References}

Alsbeih G, El-Sebaie M, Al-Harbi N, Al-Buhairi M, Al-Hadyan K \& Al-Rajhi N 2007 Radiosensitivity of human fibroblasts is associated with amino acid substitution variants in susceptible genes and correlates with the number of risk alleles. International Journal of Radiation Oncology, Biology, Physics 68 229-235.

Angele S, Romestaing P, Moullan N, Vuillaume M, Chapot B, Friesen M, Jongmans W, Cox DG, Pisani P, Gerard JP et al. 2003 ATM haplotypes and cellular response to DNA damage: association with breast cancer risk and clinical radiosensitivity. Cancer Research 63 8717-8725.

Bennett B, Repacholi M \& Carr Z 2006 Health Effects of the Chernobyl Accident and Special Health Care Programmes. Geneva: WHO Press.

Boltze C, Roessner A, Landt O, Szibor R, Peters B \& Schneider-Stock R 2002 Homozygous proline at codon 72 
of p53 as a potential risk factor favoring the development of undifferentiated thyroid carcinoma. International Journal of Oncology 21 1151-1154.

Bouville A, Likhtarev IA, Kovgan L, Minenko VF, Shinkarev SM \& Drozdovitch V 2007 Radiation dosimetry for highly contaminated Belarusian, Russian and Ukranian populations, and for less contaminated populations in Europe. Health Physics 93 487-501.

Cardis E, Kesminiene A, Ivanov V, Malakhova I, Shibata Y, Khrouch V, Drozdovitch V, Maceika E, Zvonova I, Vlassov O et al. 2005 Risk of thyroid cancer after exposure to ${ }^{131} \mathrm{I}$ in childhood. Journal of the National Cancer Institute 97 724-732.

Davies L \& Welch HG 2006 Increasing incidence of thyroid cancer in the United States, 1973-2002. Journal of the American Medical Association 295 2164-2167.

Davis S, Stepanenko V, Rivkind N, Kopecky KJ, Voilleque P, Shakhtarin V, Parshkov E, Kulikov S, Lushnikov E, Abrosimov A et al. 2004 Risk of thyroid cancer in the Bryansk oblast of the Russian Federation after the Chernobyl Power Station accident. Radiation Research 162 241-248.

Detours V, Delys L, Libert F, Weiss Solis D, Bogdanova T, Dumont JE, Franc B, Thomas G \& Maenhaut C 2007 Genome-wide gene expression profiling suggests distinct radiation susceptibility in sporadic and post-Chernobyl papillary thyroid cancers. British Journal of Cancer 97 818-825.

Detours V, Versteyhe S, Dumont JE \& Maenhaut C 2008 Gene expression profiles of post-Chernobyl thyroid cancers. Current Opinion in Endocrinology, Diabetes, and Obesity 15 440-445.

Duell EJ, Millikan RC, Pittman GS, Winkel S, Lunn RM, Tse CK, Eaton A, Mohrenweiser HW, Newman B \& Bell DA 2001 Polymorphisms in the DNA repair gene XRCC1 and breast cancer. Cancer Epidemiology, Biomarkers \& Prevention 10 217-222.

Edvardsen H, Tefre T, Jansen L, Vu P, Haffty BG, Fossa SD, Kristensen VN \& Borresen-Dale AL 2007 Linkage disequilibrium pattern of the ATM gene in breast cancer patients and controls; association of SNPs and haplotypes to radio-sensitivity and post-lumpectomy local recurrence. Radiation Oncology 225.

Figueiredo JC, Knight JA, Briollais L, Andrulis IL \& Ozcelik H 2004 Polymorphisms XRCC1-R399Q and XRCC3-T241M and the risk of breast cancer at the Ontario site of the Breast Cancer Family Registry. Cancer Epidemiology, Biomarkers \& Prevention 13 583-591.

Granja F, Morari J, Morari EC, Correa LA, Assumpcao LV \& Ward LS 2004 Proline homozygosity in codon 72 of p53 is a factor of susceptibility for thyroid cancer. Cancer Letters 210 151-157.

Hall EJ, Schiff PB, Hanks GE, Brenner DJ, Russo J, Chen J, Sawant SG \& Pandita TK 1998 A preliminary report: frequency of $\mathrm{A}-\mathrm{T}$ heterozygotes among prostate cancer patients with severe late responses to radiation therapy. Cancer Journal from Scientific American 4 385-389.

Han S, Zhang HT, Wang Z, Xie Y, Tang R, Mao Y \& Li Y 2006 DNA repair gene XRCC3 polymorphisms and cancer risk: a meta-analysis of 48 case-control studies. European Journal of Human Genetics 14 1136-1144.

Heikkinen K, Rapakko K, Karppinen SM, Erkko H, Nieminen P \& Winqvist R 2005 Association of common ATM polymorphism with bilateral breast cancer. International Journal of Cancer 116 69-72.

Hillebrandt S, Streffer C, Demidchik EP, Biko J \& Reiners C 1997 Polymorphisms in the p53 gene in thyroid tumours and blood samples of children from areas in Belarus. Mutation Research 381 201-207.

Hoeijmakers JH 2001 Genome maintenance mechanisms for preventing cancer. Nature 411 366-374.

Hosking L, Lumsden S, Lewis K, Yeo A, McCarthy L, Bansal A, Riley J, Purvis I \& Xu CF 2004 Detection of genotyping errors by Hardy-Weinberg equilibrium testing. European Journal of Human Genetics 12 395-399.

Hu JJ, Smith TR, Miller MS, Lohman K \& Case LD 2002 Genetic regulation of ionizing radiation sensitivity and breast cancer risk. Environmental and Molecular Mutagenesis 39 208-215.

Hu Z, Ma H, Chen F, Wei Q \& Shen H 2005 XRCC1 polymorphisms and cancer risk: a meta-analysis of 38 case-control studies. Cancer Epidemiology, Biomarkers \& Prevention 14 1810-1818.

Jacob P, Bogdanova TI, Buglova E, Chepurniy M, Demidchik Y, Gavrilin Y, Kenigsberg J, Meckbach R, Schotola C, Shinkarev S et al. 2006 Thyroid cancer risk in areas of Ukraine and Belarus affected by the Chernobyl accident. Radiation Research 165 1-8.

Khanna KK \& Jackson SP 2001 DNA double-strand breaks: signaling, repair and the cancer connection. Nature Genetics 27 247-254.

Khrunin AV, Tarskaia LA, Spitsyn VA, Lylova OI, Bebyakova NA, Mikulich AI \& Limborska SA 2005 p53 polymorphisms in Russia and Belarus: correlation of the 2-1-1 haplotype frequency with longitude. Molecular Genetics and Genomics 272 666-672.

Likhtarev I, Bouville A, Kovgan L, Luckyanov N, Voilleque P \& Chepurny M 2006 Questionnaire- and measurement-based individual thyroid doses in Ukraine resulting from the Chornobyl nuclear reactor accident. Radiation Research 166 271-286.

Malmer BS, Feychting M, Lonn S, Lindstrom S, Gronberg H, Ahlbom A, Schwartzbaum J, Auvinen A, CollatzChristensen H, Johansen C et al. 2007 Genetic variation in p53 and ATM haplotypes and risk of glioma and meningioma. Journal of Neuro-oncology 82 229-237.

Nikiforov YE, Nikiforova MN, Gnepp DR \& Fagin JA 1996 Prevalence of mutations of ras and p53 in benign and malignant thyroid tumors from children exposed to radiation after the Chernobyl nuclear accident. Oncogene 13 687-693. 
Nikiforov YE, Rowland JM, Bove KE, Monforte-Munoz H \& Fagin JA 1997 Distinct pattern of ret oncogene rearrangements in morphological variants of radiationinduced and sporadic thyroid papillary carcinomas in children. Cancer Research 57 1690-1694.

Pietsch EC, Humbey O \& Murphy ME 2006 Polymorphisms in the p53 pathway. Oncogene 25 1602-1611.

Pim D \& Banks L 2004 p53 polymorphic variants at codon 72 exert different effects on cell cycle progression. International Journal of Cancer 108 196-199.

Rabes HM, Demidchik EP, Sidorow JD, Lengfelder E, Beimfohr C, Hoelzel D \& Klugbauer S 2000 Pattern of radiation-induced RET and NTRK1 rearrangements in 191 post-Chernobyl papillary thyroid carcinomas: biological, phenotypic, and clinical implications. Clinical Cancer Research 6 1093-1103.

Rogounovitch TI, Saenko VA, Ashizawa K, Sedliarou IA, Namba H, Abrosimov AY, Lushnikov EF, Roumiantsev PO, Konova MV, Petoukhova NS et al. 2006 TP53 codon 72 polymorphism in radiation-associated human papillary thyroid cancer. Oncology Reports 15 949-956.

Ron E, Lubin JH, Shore RE, Mabuchi K, Modan B, Pottern LM, Schneider AB, Tucker MA \& Boice JD Jr 1995 Thyroid cancer after exposure to external radiation: a pooled analysis of seven studies. Radiation Research 141 259-277.

Rothman KJ \& Greenland S 1998 Modern Epidemiology. 2nd edn. Philadelphia: Lipincott-Raven.

Shiloh Y 2003 ATM and related protein kinases: safeguarding genome integrity. Nature Reviews. Cancer 3 155-168.

Siddique MM, Barlam C, Fiszer-Maliszewska L, Aggarwal A, Tan A, Tan P, Soo KC \& Sabapathy K 2005 Evidence for selective expression of the p53 codon 72 polymorphs: implications in cancer development. Cancer

Epidemiology, Biomarkers \& Prevention 14 2245-2252.

Soussi T \& Wiman KG 2007 Shaping genetic alterations in human cancer: the p53 mutation paradigm. Cancer Cell 12 303-312.

Stepanenko VF, Voilleque PG, Gavrilin YuI, Khrouch VT, Shinkarev SM, Orlov MYu, Kondrashov AE, Petin DV, Iaskova EK \& Tsyb AF 2004 Estimating individual thyroid doses for a case-control study of childhood thyroid cancer in Bryansk oblast, Russia. Radiation Protection Dosimetry 108 143-160.
Sturgis EM, Zhao C, Zheng R \& Wei Q 2005 Radiation response genotype and risk of differentiated thyroid cancer: a case-control analysis. Laryngoscope $\mathbf{1 1 5}$ 938-945.

Tamura Y, Maruyama M, Mishima Y, Fujisawa H, Obata M, Kodama Y, Yoshikai Y, Aoyagi Y, Niwa O, Schaffner W et al. 2005 Predisposition to mouse thymic lymphomas in response to ionizing radiation depends on variant alleles encoding metal-responsive transcription factor-1 (Mtf-1). Oncogene 24 399-406.

Taylor RM, Thistlethwaite A \& Caldecott KW 2002 Central role for the XRCC1 BRCT I domain in mammalian DNA single-strand break repair. Molecular and Cellular Biology 22 2556-2563.

Thorstenson YR, Roxas A, Kroiss R, Jenkins MA, Yu KM, Bachrich T, Muht D, Wayne TL, Chu G, Davis RW et al. 2003 Contributions of ATM mutations to familial breast and ovarian cancer. Cancer Research 63 3325-3333.

Wang J, Chuang K, Ahluwalia M, Patel S, Umblas N, Mirel D, Higuchi R \& Germer S 2005 High-throughput SNP genotyping by single-tube PCR with $T_{\mathrm{m}}$-shift primers. BioTechniques 39 885-893.

Williams ED 2006 Chernobyl and thyroid cancer. Journal of Surgical Oncology 94 670-677.

Yamashita S \& Saenko V 2006 Mechanisms of disease: molecular genetics of childhood thyroid cancers. Nature Clinical Practice. Endocrinology \& Metabolism 3 422-429.

Yang T, Namba H, Hara T, Takamura N, Nagayama Y, Fukata S, Ishikawa N, Kuma K, Ito K \& Yamashita S 1997 p53 induced by ionizing radiation mediates DNA end-jointing activity, but not apoptosis of thyroid cells. Oncogene 14 1511-1519.

Yen CY, Liu SY, Chen CH, Tseng HF, Chuang LY, Yang CH, Lin YC, Wen CH, Chiang WF, Ho CH et al. 2008 Combinational polymorphisms of four DNA repair genes XRCC1, XRCC2, XRCC3, and XRCC4 and their association with oral cancer in Taiwan. Journal of Oral Pathology \& Medicine 37 271-277.

Yoon YJ, Chang HY, Ahn SH, Kim JK, Park YK, Kang DR, Park JY, Myoung SM, Kim do Y, Chon CY et al. 2008 MDM2 and p53 polymorphisms are associated with the development of hepatocellular carcinoma in patients with chronic hepatitis B virus infection. Carcinogenesis 29 1192-1196. 